\title{
The optimality of nominal contracts ${ }^{\star}$
}

\author{
Scott Freeman ${ }^{1}$ and Guido Tabellini ${ }^{2}$ \\ ${ }^{1}$ Department of Economics, University of Texas, Austin, TX 78712, USA \\ ${ }^{2}$ Universitá Bocconi and Innocenzo Gasparini Institute for Economic Research, \\ via Salasco 5, I-20136 Milano, ITALY
}

Received: March 29, 1996; revised version: February 25, 1997

Summary. This paper presents a model in which agents choose to use money as a medium of exchange, a means of payment, and a unit of account. The paper defines conditions under which nominal contracts, promising future payment of a fixed number of units of fiat money, prove to be the optimal contract form in the presence of either relative or aggregate price risk. When relative prices are random, nominal contracts are optimal if individuals have ex ante similar preferences over future consumption. When the aggregate price level is random, whether from shocks to the money supply or aggregate output, nominal contracts (perhaps coupled with equity contracts) lead to optimal risk-sharing if individuals have the same degree of relative risk aversion. Finally, nominal contracts may be optimal if the repayment of contracts is subject to a binding cash-in-advance constraint. In this case, a contingent contract increases the risk of holding excessive cash balances.

JEL Classification Numbers: E43, E44, D91.

\section{Introduction}

One of the greatest economic puzzles in an age of widely varying, random rates of inflation is the persistent use of nominal contracts, that is, of promises of a future payment of a prespecified, uncontingent sum of fiat money. The goal of this paper is to suggest reasons why such contracts might represent the optimal contract form in a large class of environments. We do not claim to

\footnotetext{
^ Parts of this paper were written while Freeman was visiting the Federal Reserve Bank of Minneapolis and the Innocenzo Gasparini Institute for Economic Research. We are grateful to Domenico Siniscalco, Neil Wallace, and seminar participants at the Institute for helpful comments. The views expressed herein do not necessarily reflect those of the Federal Reserve System.
} 
have found the single explanation for the widespread use of nominal contracts, nor are we certain that a single explanation can be found. ${ }^{1}$ However, the paper identifies some potential benefits of nominal contracts that, together with other factors, can account for their use in specific instances.

The starting point of our analysis is the observation that every individual is generally a party to several contracts with several other individuals. Hence, in this paper we study a general equilibrium model in which parties to a contract choose a preferred contract form given the contract form elsewhere in the economy. We consider two kinds of shocks and identify conditions under which nominal contracts lead to optimal risk sharing. One induces a relative price shock, the other an aggregate price level shock. We show that there are reasonable economic environments in which nominal contracts are not inferior to contracts contingent on either shock.

Perhaps our most surprising result is the optimality of nominal contracts in the presence of price level shocks. If the contracting parties have the same degree of constant relative risk aversion, then a system of nominal contracts can optimally share the risk of aggregate price level shocks. The reason is that, with the same degree of constant relative risk aversion, it is optimal to share risk in proportion to net wealth. This is what nominal contracts do, if all private contracts are nominal and all outside assets are also nominal.

Departures from constant relative risk aversion imply that there are gains from having contracts contingent on aggregate shocks. But these gains are generally a second order of magnitude, because in general optimal risk sharing still requires wealthier individuals to bear more risk, though not necessarily in proportion to their wealth. Hence, small costs of incorporating contingencies may restore optimality of fixed nominal contracts, even if individuals differ in their risk attitudes.

With respect to relative price shocks, the optimality of nominal contracts follows from our assumption that individuals are ex-ante identical with respect to such shocks. As a consequence they do not (cannot) wish to insure each other against this realization.

We formalize our reasoning in a fully specified, general equilibrium model of spatially separated agents who borrow and lend, choosing to specify fiat money as the means of payment by which IOUs are settled. In several nontrivial circumstances, fiat money also serves as the unit of account, i.e., IOUs promising a fixed nominal sum of fiat money are an optimal contract form.

The paper outline is as follows. Section 2 lays out the model of an overlapping generations economy with spatially separated agents born in each generation. Section 3 proves the optimality of nominal contracts when there are only relative price shocks and future preferences are unknown. The general properties of an equilibrium with nominal contracts are described in section 4. In section 5, we show that nominal contracts lead to optimal

\footnotetext{
${ }^{1}$ Others who have asked why nominal uncontingent contracts are so widespread have focussed on labor markets rather than financial markets. These include Azariadis and Cooper (1985), Cooper (1988,1990), Gottfries (1990), Haubrich and King (1991), and Smith (1989).
} 
sharing of aggregate risk if individuals have the same risk preferences. Finally, section 6 contains some concluding remarks.

\section{The model}

This section describes the economic environment. A growing population is distributed over a large, even number $I$ of contiguous islands. The islands are located in a circle and are numbered consecutively in a clockwise direction around the circle according to the variable $i, i=1,2, \ldots, I$. There is a separate market in each island; no centralized "inter-island" market exists. Households, each comprising two partners, live two periods. A new generation is born every period. Each household is endowed with one unit of nonstorable output when young and nothing when old.

The population of newborn households on each island is random. An island can either be "large" or "small." A large island receives a number $N_{t}$ of newborn households in period $t$; a small island receives a number $\theta N_{t}$ of newborn households, where $\theta<1$. This assumption is needed to have heterogeneity within the same generation. Whether an island is large or small in period $t$ is determined by the realization of the random variable $\omega_{t}$. For simplicity, $\omega_{t}$ can only take two values, 1 and 2 , with equal probability. If $\omega_{t}=1$, then all islands for which $i$ is even are large in period $t$, and all islands for which $i$ is odd are small. If $\omega_{t}=2$, then the opposite is true. Because the total number of islands, $I$, is assumed to be even, the total population size does not depend on the realization of $\omega_{t}$.

Each island produces a different commodity. This difference matters because the preferences of each household depend on its location on the circle. When young, a household born in island $i$ wants only to consume the commodity produced on island $i+1$. Except for their location, all young households are identical. ${ }^{2}$ Commodities are not transportable - the young travel to the neighboring island in order to consume the desired commodity.

When old, each household moves to some other island, whose commodity it wants to consume. ${ }^{3}$ When young, the household does not yet know where it will move when old. Its destination when old depends on a preference shock that it will experience in the second and last period of its life. An old household learns its destination only after it has left the island on which it was born. The realization of the preference shock is private information and cannot be learned by others. Each old individual has the same probability of moving to an odd or an even island, and the same number of old consumers moves to each island.

\footnotetext{
${ }^{2}$ Townsend (1987) studies a related model with spatially separated individuals in an overlapping generations economy. However in his model, unlike here, neighboring individuals only meet once in their lifetime, and hence cannot write IOU contracts among themselves.

${ }^{3}$ The random assignment of agents to other islands follows the models of Townsend (1989) and Mitsui and Watanabe (1990).
} 
This set up seems complex, but it has an important simplifying implication. Individuals only differ by the island in which they are born. Since the only relevant difference between islands is whether they are large (L) or small (S), we can write the expected utility function of an old household without reference to odd or even locations and to its preference shock. Moreover, every household has the same probability of ending up in a small or large island when old. Thus, there are only two types of households: those born in a small or in a large island. The expected utility of a household born in period $t$ on an island of type $k$, for $k=S, L$ is:

$$
U\left(x_{t}^{k}\right)+\frac{1}{2} \sum_{w_{t+1}=1}^{2} V\left(c_{t+1}^{k}\left(\omega_{t+1}\right)\right)=U\left(x_{t}^{k}\right)+\frac{1}{2} V\left(c_{t+1}^{k}(1)\right)+\frac{1}{2} V\left(c_{t+1}^{k}(2)\right)
$$

where $x_{t}^{k}$ and $c_{t+1}^{k}$ denote its consumption when young and old, respectively, and where $U(\cdot)$ and $V(\cdot)$ are twice-continuously differentiable, strictly increasing, and strictly concave functions. Notice that $1 / 2$ is the probability of ending up on either type of island when old.

Each period is split into two sub-periods. In the first sub-period everybody observes the realization of the shock $\omega$ and one partner of each household (young and old) starting on island $i$ travels to island $i+1 .^{4}$ In the second sub-period the traveling partner returns, old households move to another island. This structure of travel and the specified preferences generate the following trading pattern for a household born on island $i$. The pattern is outlined here and charted in Fig. 1.

\section{1) Youth}

i) First sub-period.

- each household is split into two units, a buyer and a seller;

the buyer travels to island $i+1$ and makes purchases by issuing IOUs payable next period; the seller remains on island $i$ and sells his commodity against IOUs receivable in the next period to the young buyers coming from island $i-1$.

(ii) Second sub-period.

- the home commodity is sold for fiat money to the arriving old households.

\section{2) Old age}

i) First sub-period.

- the household is again split into two, a debt collector and a debt repayer; the debt repayer travels to island $i+1$ and repays the household's IOUs with fiat money; the debt collector remains on its island and collects the fiat money repayment of the IOUs of island $i-1$.

\footnotetext{
${ }^{4}$ The division of a household into a partner who travels and one who stays is adapted from a model attributed to Robert E. Lucas, Jr. by Townsend (1980).
} 
First sub-period

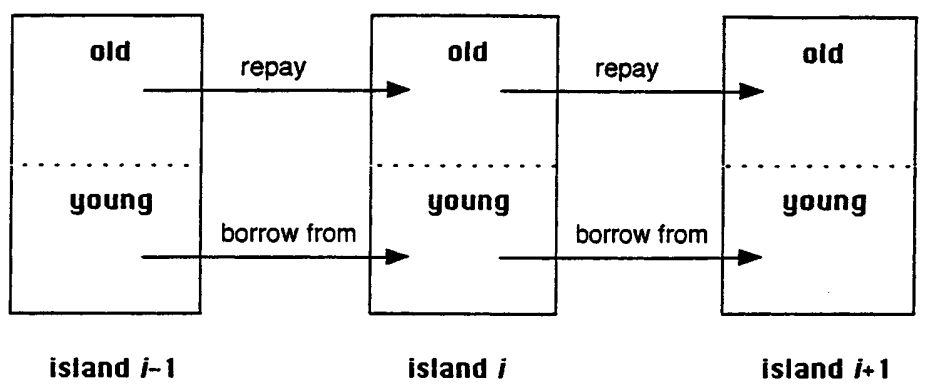

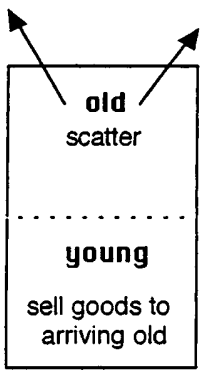

island $i-1$

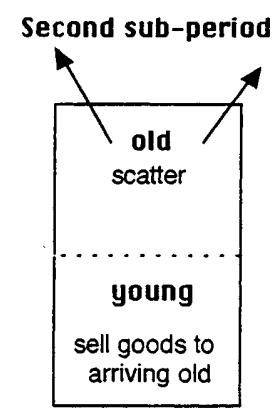

island $i$

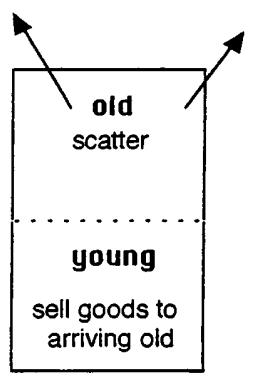

island $i+1$

Figure 1

ii) Second sub-period.

- the two partners reunite and travel to some other island;

- the household purchases the commodity of the destination island with fiat money, then consumes it.

On each island is a local police authority that can enforce any form of contract between two parties when both parties are currently on that island. These island-based authorities cannot communicate with the authorities and agents on other islands or otherwise enforce contracts at a distance. This implies that there is not a centralized market for IOUs; the technology for enforcing contracts can be applied between contiguous islands but not across all islands.

The absence of a central market means that the spatial and temporal separation of households has several fundamental implications for trade and credit. First, transactions when young can only be made through a consumption loan among households belonging to the same generation. We can then ask what is the optimal contractual form of such a loan. Second, each 
household is a party to two contracts, one on each side of its balance sheet. This feature is realistic and also relevant for the results. Third, the contracting parties are different, in that they are born in islands of different size and hence, as will be clear below, have different net financial wealth. This creates an opportunity for risk sharing. Finally, contracts can only be settled by fiat money; this, too, will become clearer below, and will also contribute to determine the optimal contract form - see section 6 .

In the initial period (period 0 ) there is a generation of households of size $N_{0}$, equally distributed among all islands, that simply wish to maximize consumption on the island where they are located. This initial old generation cannot trade until the second sub-period of the initial period. It has no endowment of goods but owns a total of $N_{0} M_{0}$ units of fiat money on each island, implying an initial aggregate money supply equal to $M_{0}=I N_{0} M_{0}$.

The aggregate money supply is assumed to grow at the constant (gross) rate $z=M_{t} / M_{t-1}$. Increases in the fiat money stock are distributed equally over all islands and used to purchase goods for government consumption. The level of government consumption is exogeneously determined and has no direct effect on the utility of individual households. Aggregate population grows at the constant rate $n=N_{t} / N_{t-1}$. Shocks to population growth and to money supply growth are studied in section 5 .

Let $b^{k}$ and $a^{k}$ denote the nominal value of the IOU issued and accepted respectively by a young household born in an island of type $k$, and let $m^{k}$ be the quantity of money that he holds, for $k=L, S$. Then we can write his budget constraints when young as

$$
\begin{array}{ll}
b_{t}^{k} \geq p_{t}^{h} x_{t}^{k} & h, k=L, S, \quad h \neq k \\
p_{t}^{k} \geq m_{t}^{k}+a_{t}^{k} & k=L, S
\end{array}
$$

where $p^{h}$ and $p^{k}$ are the money prices of the goods sold in an island of type $h$ and $k$ respectively.

When old, the consumer faces the budget constraint:

$$
\begin{gathered}
p_{t+1}\left(\omega_{t+1}\right) c_{t+1}^{K} \leq m_{t}^{k}+R_{t+1}^{h}\left(\omega_{t+1}\right) a_{t}^{k}-R_{t+1}^{k}\left(\omega_{t+1}\right) b_{t}^{k} \equiv F_{t+1}^{k}\left(\omega_{t+1}\right), \\
h, k=S, L, h \neq k
\end{gathered}
$$

where $R_{t+1}^{k}\left(\omega_{t+1}\right), R_{t+1}^{h}\left(\omega_{t+1}\right)$ are the possibly state-contingent, gross nominal rates of return on the IOUs issued by individuals born in islands of type $k$ and $h$ respectively, $F_{t+1}\left(\omega_{t+1}\right)$ denotes net nominal financial wealth, and $p_{t+1}\left(\omega_{t+1}\right)$ is the price faced by the consumer when old, which depends on whether he ends up on a large or small island, and hence on the realizations of the state $\omega_{t+1}$ (as well as on his preference shock, which we omit here to simplify notation). We allow nominal rates of return to be contingent on the observation of the state. If $R_{t+1}^{j}$ is not contingent on the realization of any shock, then we say that the IOU is a "nominal contract," since it is a promise to pay a fixed amount of money tomorrow, irrespective of the state of the world. Note that since the preference shock is private information, individ- 
uals cannot write IOUs contingent on the realization of these shocks. In addition, IOUs cannot be contingent on a household's consumption because that occurs on a separate island after the IOU is redeemed. The question of whether equilibrium contracts will be contingent on the shock $\omega_{t+1}$, which determines which islands are large and which are small, is addressed in the next section.

The previous assumptions about timing have a straightforward but important implication for the nature of an equilibrium. Namely, only fiat money will be accepted in payment for an IOU. ${ }^{5}$ The reason is that the old, who are scattered among the islands, need fiat money to carry out their consumption purchases when old. In particular, because of the spatial separation between islands, a payable IOU cannot be settled by offering in exchange an IOU issued by some other island because the spatial separation prevents the redemption of this second IOU before the death of its issuer. Hence, the settlement of an IOU is subject to a cash-in-advance constraint imposed by the spatial separation, which can be written as:

$$
R_{t+1}^{k}\left(\omega_{t+1}\right) b_{t}^{k} \leq m_{t}^{k}, k=L, S
$$

The equilibrium conditions in the securities markets of each island are:

$$
\begin{aligned}
\theta a_{t}^{S} & =b_{t}^{L} \\
a_{t}^{L} & =\theta b_{t}^{S}
\end{aligned}
$$

In writing (2.5) we have used the fact that the young population in a small island is a fraction $\theta$ of the population in a large island.

Since at the start of any period fiat money is held only by the old, and since by assumption the old are drawn equally from all islands, the money supply in each island is $N_{0} M_{t}$. With aggregate population growing at the (gross) rate $n$ and with money supply growing at the (gross) rate $z$, the equilibrium condition in the money market of each island is

$$
\begin{aligned}
\theta m_{t}^{S} & =M_{0}(z / n)^{t} \\
m_{t}^{L} & =M_{0}(z / n)^{t}
\end{aligned}
$$

An implication of the market clearing conditions (2.5) and (2.6) is that the aggregate nominal wealth of the old must equal the total stock of fiat money

$$
\left[\theta F^{S}\left(\omega_{t+1}\right)+F^{L}\left(\omega_{t+1}\right)\right] I N_{t} / 2=\bar{M}_{t}=I N_{0} M_{t}
$$

or

$$
\theta F^{S}\left(\omega_{t+1}\right)+F^{L}\left(\omega_{t+1}\right)=2 M_{0}(z / n)^{t} .
$$

We can now define a rational expectations competitive equilibrium with optimal contracts (hereafter, simply "equilibrium") as a sequence of the

\footnotetext{
${ }^{5}$ The model also has a nonmonetary equilibrium in which fiat money exists but is not valued. In this nonmonetary equilibrium, IOUs cannot be redeemed for something valued and therefore none will be accepted.
} 
vector $\left[R_{t+1}^{S}, p_{t}^{S}, b_{t}^{S}, a_{t}^{S}, m_{t}^{S}, x_{t}^{S}, c_{t}^{S}, R_{t+1}^{L}, p_{t}^{L}, b_{t}^{L}, a_{t}^{L}, m_{t}^{L}, x_{t}^{L}, c_{t}^{L}\right]$ such that i) young households choose money balances, IOUs payable and receivable, and consumption to maximize expected utility taking prices and interest rates as given; ii) IOUs take a form such that it is not possible to increase the expected utility of a member of any generation $t$ without reducing the expected utility of another member of that generation; iii) each household maximizes expected utility basing its decisions on the probability distribution actually generated by the equilibrium; iv) markets in IOUs and fiat money clear.

Since the economic environment is fairly complex, it may be useful to comment on two of its main features. First, to investigate how different contract forms share aggregate risk among the contracting parties, we need some heterogeneity in net financial wealth at the end of the first period of life. This is achieved by having islands of different size. As explained, the structure described above implies that there really are only two types of households, those born in a large or small island. Second, for the equilibrium to be stationary, we need to have the same quantity of money in each island in every period. This is achieved by assuming that an equal number of the two types of agents arrives in each island.

\section{The equilibrium contract under relative price risk}

In this section we discuss under what conditions nominal IOU contracts are optimal if the only sources of randomness are relative price risk and shocks to preferences.

Recall that an IOU contract is a "nominal contract" if its nominal rate of return is not contingent on the realization of any shock. The rate of return $R_{t+1}^{j}$ cannot be contingent on the preference shock when old, since the realization of this shock is private information and consumption is not observable. The remaining question is whether a contract for which $R_{t+1}^{j}$ is not contingent on the realization of $\omega_{t+1}$ is optimal, in the sense that it is not possible to increase the expected utility of a member of any generation $t$ without reducing the expected utility of another member of that same generation. The answer is contained in the following:

Proposition 1. If aggregate population growth and money supply growth are not random, then the nominal contract is an optimal IOU contract.

The proof is straightforward. An "optimal contract" between the households of neighboring islands maximizes the expected utility of those born on a small island for a given level of expected utility of those born on a large island, subject to the constraints and the equilibrium conditions outlined in the previous section. Consider first an equilibrium in which the cashin-advance constraints (2.4) are not binding. Then, combining (2.1) and (2.3), and noting that every household has a probability of $\frac{1}{2}$ of ending up in a large or small island, we can characterize an optimal contract as a choice of $F^{S}(\omega)$, $F^{L}(\omega)$ for each $\omega$ to maximize 


$$
E_{\infty}\left\{\frac{1}{2} V\left[\frac{F^{S}(\omega)}{p^{S}}\right]+\frac{1}{2} V\left[\frac{F^{S}(\omega)}{p^{L}}\right]+\lambda\left[V^{*}-\left[\frac{1}{2} V\left(\frac{F^{L}(\omega)}{p^{S}}\right)+\frac{1}{2} V\left(\frac{F^{L}(\omega)}{p^{L}}\right)\right]\right]\right\}
$$

subject to $\theta F^{S}(\omega)+F^{L}(\omega)=2 M_{0}(z / n)^{t}$, for $\omega=1,2$ and where $E_{\infty}$ is the expectations operator with respect to $\omega$. Notice that we have used the symmetry of the model to write $p^{S}$ and $p^{L}$ as independent of $\omega$.

The resulting first order conditions may be written as

$$
V^{\prime}\left[\frac{F^{S}(\omega)}{p^{S}}\right] / p^{S}+V^{\prime}\left[\frac{F^{S}(\omega)}{p^{L}}\right] / p^{L}=\theta \lambda\left\{V^{\prime}\left[\frac{F^{L}(\omega)}{p^{S}}\right] / p^{S}+V^{\prime}\left[\frac{F^{L}(\omega)}{p^{L}}\right] / p^{L}\right\}
$$

for $\omega=1,2$ and for every $t$.

This condition is satisfied by $F^{S}(\omega)=F^{S}$ and $F^{L}(\omega)=F^{L}$ for all realizations of $\omega$. From the definitions of $F^{S}(\omega)$ and $F^{L}(\omega)$ in (2.3), we see that they are not contingent on $\omega$ if $R^{S}$ and $R^{L}$ are not contingent on $\omega$. Hence a nominal contract is optimal.

If the cash-in-advance constraint (2.4) is binding, imposing an opportunity cost on the holding of money balances, then a fortiori a nominal contract is optimal. A contingent contract requires that the cash balances held equal the largest nominal contingent payment called for by the contract. If the cash-in-advance constraint is binding, contingent contracts have the effect of increasing money balances and thus this opportunity cost. ${ }^{6}$

The intuition underlying Proposition 1 is also straightforward. Suppose that $R_{t+1}^{j}$ is not contingent on $\omega_{t+1}$, and consider the expected utility of an old individual, conditional on the realization of $\omega_{t+1}$, but not on that of the preference shock. By assumption every old individual has the same probability of traveling to an odd or an even island. But then, whether odd islands are small and even islands are large, or vice versa, is irrelevant: the realization of $\omega_{t+1}$ does not affect this expected utility. Hence, an IOU contract contingent on $\omega_{t+1}$ alone cannot achieve any relevant risk sharing among individuals born in contiguous islands. A contract contingent on both $\omega_{t+1}$ and the destinations of the old (the preference shock) could. But such a contract is ruled out by an incentive compatibility condition, since the destinations of the old are not publicly observable ex-post. ${ }^{7}$ Therefore, given this incentive constraint, a nominal IOU contract is optimal.

We should note that the symmetry of the model plays a crucial role in the proof of this proposition. Suppose, for instance, that individuals born in an odd island have a probability greater than $\frac{1}{2}$ of going to an odd island when old, and conversely that individuals born in an even island are more likely to go to an even island when old. It is easy to show in this case that individuals

\footnotetext{
${ }^{6}$ This is further discussed in a previous version of this paper.

${ }^{7}$ Alternatively, we could have made the simpler but more restrictive assumption that the destination when old is learned only upon arrival (i.e., after the IOU's are paid).
} 
born in contiguous islands wish to insure each other against the relative price shock by writing IOU contracts contingent on the realization of $\omega$. Hence nominal contracts are no longer optimal, even if the preference shock is unobservable.

It is not important to the optimality of nominal contracts that all goods are equally likely to be consumed by old households. This assumption merely makes the description of equilibrium more symmetric and thus more tractable. What is important is that households face the same probability of wanting any particular type of good. If a household is ex ante more likely than the rest of the population to want some good, it will have an incentive to write a contract that will pay him more when the price of that good is revealed to be high.

The general lesson to be drawn from this section is that contingent contracts can provide insurance against relative price risk only if individuals are sufficiently different from each other in an ex-ante sense. Which relative price risk one needs to insure against is often ex-ante unknown to the contracting parties. There are many consumption decisions, like going to a movie versus going out for dinner, which are difficult to predict in advance. These decisions are determined by random events that are private information, and which therefore cannot be incorporated in any contingent contract. If individuals face the same relative price risk, nominal contracts are optimal. This need not mean that they share identical expectations about future consumption of every good. They must merely have the same uncertainty about whether they will consume goods expensive in each state. For example, if both cars and trucks are expensive in the same states of the world, a nominal contract will be optimal between two parties, one with a $50 \%$ chance of wanting a car next period and the other with a $50 \%$ chance of wanting a truck in the next period.

Random relative prices present the household with two types of risk - the risk that it will want to purchase an expensive good and the risk to the value of its assets. The first type of risk is uninsurable because it is a shock to unobservable preferences. Therefore, the best that a household can do is to minimize the risk to the value of its assets by fixing the number of dollars it will have available for consumption when old. A system of contingent contracts with offsetting contingencies that leave each household with the same number of dollars in each state can accomplish this but in a needlessly complicated way that requires the verification of the state. Contracts promising fixed quantities of goods would expose the household to the risk that the goods it is promised have a low value. In addition, because payment must be made with fiat money, contracts fixed in goods require the verification of prices and thus of the state. Only nominal contracts avoid both the risk to a household's wealth and the verification of the state. 


\section{Properties of the equilibrium}

This section outlines some general properties of the equilibrium, including the valuation of the equilibrium contracts. We retain the assumption that there is no aggregate risk, so that nominal contracts are optimal and $R_{t+1}^{k}\left(\omega_{t+1}\right)=R_{t+1}^{k}$. Under this assumption, a young household born at time $t$ in an island of type $k, k=S, L$, maximizes:

$$
U\left(b_{t}^{k} / p_{t}^{h}\right)+\frac{1}{2} V\left(F_{t+1}^{k} / p_{t+1}^{k}\right)+\frac{1}{2} V\left(F_{t+1}^{k} / p_{t+1}^{h}\right), \quad h=S, L ; h \neq k
$$

by choice of $m_{t}^{k}, b_{t}^{k}$ and $a_{t}^{k}$, subject to (2.2)-(2.4).

The first order conditions are:

$$
\begin{gathered}
U^{\prime}\left(b_{t}^{k} / p_{t}^{h}\right)=R_{t+1}^{k} R_{t+1}^{h} \pi_{t+1}^{h}\left[V^{\prime}\left(F_{t+1}^{k} / p_{t+1}^{k}\right) \frac{p_{t+1}^{h}}{p_{t+1}^{k}}+V^{\prime}\left(F_{t+1}^{k} / p_{t+1}^{h}\right)\right] \\
\left(R_{t+1}^{h}-1\right)\left[V^{\prime}\left(F_{t+1}^{k} / p_{t+1}^{k}\right) \frac{1}{p_{t+1}^{k}}+V^{\prime}\left(F_{t+1}^{k} / p_{t+1}^{h}\right) \frac{1}{p_{t+1}^{h}}\right]=2 \mu_{t}^{k} \frac{1}{p_{t}}
\end{gathered}
$$

where $\pi_{t+1}^{h} \equiv p_{t}^{h} / p_{t+1}^{h}$ is the inverse of the (gross) inflation rate in the price of the good produced in an island of type $h$, and $\mu_{t}^{k}$ is the Lagrange multiplier of the cash-in-advance constraint (2.4), written in real terms. Thus, not surprisingly, if the cash-in-advance constraint does not bind for the consumers born in island $k$ (if $\mu_{t}^{k}=0$ ), then the (gross) lending rate in that island equals unity $\left(R_{t+1}^{h}=1\right)$. And conversely, if the cash-in-advance constraint binds (if $\left.\mu_{t}^{k}>0\right)$, then IOUs receivable earn a positive rate of return $\left(R_{t+1}^{h}>1\right)$ even though fiat money is valued. ${ }^{8}$

Section 1 of the appendix characterizes a stationary equilibrium, namely a constant equilibrium allocation supported by constant relative prices, interest rates and inflation rate. Let $q^{k}$ be the real money balances demanded by the young born in an island of type $k$ in such equilibrium. Then the clearing of the money market in each type of island at $t$ requires

$$
\theta p_{t}^{S} q^{S}=p_{t}^{L} q^{L}=\bar{M}_{t} / N_{t} \equiv M_{0}(z / n)^{t}, \quad k=S, L
$$

Imposing (4.3) for periods $t$ and $t+1$ and taking ratios of the demand and supply for money in both periods, we obtain that the inverse of the inflation rate in the stationary equilibrium is $\pi \equiv p_{t} / p_{t+1}=n / z$ for all $t$.

It is proved in the appendix that in a neighborhood of $\theta=1$, the Lagrange multiplier $\mu^{k}$ is non-increasing in $\pi$, and strictly decreasing if $\mu^{k}>0$. Intuitively, as the inflation rate rises (as $\pi$ drops), individuals try to reduce

\footnotetext{
${ }^{8} \mathrm{~A}$ cash discount would be equivalent to $R_{t+1}^{h}>1$.
} 
their holdings of real cash balances. At some point the cash-in-advance constraint starts to bind, and when that happens nominal interest rates on the IOU contracts rise above unity. As inflation keeps rising, the cash-inadvance constraint becomes more and more binding, and $\mu^{k}$ increases. $^{9}$

\section{Equilibrium contracts with aggregate randomness}

Aggregate output shocks: We now discuss the desirability of nominal contracts when there is randomness in aggregate output or in the fiat money stock. As an example of an economy with randomness in aggregate output, suppose that the (gross) rate of population growth, $n_{t}=N_{t} / N_{t-1}$, is an always positive i.i.d. random variable, while the stock of fiat money grows at the constant rate $z$, as in the previous sections. In this section we consider equilibria in which the cash-in-advance constraint is not binding. Equilibria with binding cash-in-advance constraints are studied in the next section.

The stationary distribution of growth rates of population ensures the existence of a stationary equilibrium like the one described in the previous section. In particular, repeating the argument of the previous section, the inverse of the inflation rate between $t$ and $t+1$ is:

$$
\pi_{t}^{k} \equiv p_{t}^{k} / p_{t+1}^{k}=\frac{M_{t} / q^{k} N_{t}}{M_{t+1} / q^{k} N_{t+1}}=n_{t+1} / z
$$

In addition, the equilibrium relative price between the commodities sold in large and small islands is unaffected by the aggregate shock, since by (4.3) it is given by: $p_{t}^{L} / p_{t}^{S}=\theta q^{S} / q^{L}$ for all $t$. Thus, the risk to the value of fiat money posed by the aggregate population shocks strikes money-holders belonging to the same generation in the same way, irrespective of where they are born. A large realization of $n_{t+1}$ makes households from both large and small islands of generation $t$ better off by increasing the value of their real money balances, while for a small realization of $n_{t+1}$ both members of generation $t$ are worse off. Therefore, this aggregate risk cannot be insured away,

\footnotetext{
${ }^{9}$ In this economy, a liquidity crunch (i.e., a more binding cash-in-advance constraint) is associated with higher (and not lower) real money balances. Intuitively, as the cash-in-advance constraint becomes more binding, young households reduce their demand of consumption loans. The equilibrium counterpart is that more goods are sold for cash (to the old) and less for credit (to the young) so that real money balances increase. This feature of the model, which is not entirely implausible, is due to the fact that the cash-in-advance constraint binds the repayment of consumption loans, rather than the purchase of consumer goods, as in the familiar models of Lucas (1980) and Svensson (1983). We conjecture that, with a labor-leisure choice when young, the real money balances will no longer always increase with expected inflation, even though $\mu^{k}$ would.
} 
but it can only be shared between households born in different islands and belonging to the same generation. The question we want to address is which contract form achieves optimal risk sharing.

If all islands are alike (if $\theta=1$ ), then all members of the same generation are identical. In this case optimal risk sharing requires that everybody faces exactly the same risk. Since every individual is a party to two opposite contracts, optimal risk sharing imposes only the general requirement that exactly the same contingencies be incorporated in every contract, so that each is left with the same net nominal money balances. When this requirement is satisfied, the effect of the aggregate shock on the two IOU contracts written by every individual offset each other exactly; the aggregate shock then only affects individual welfare by changing the purchasing power of real money balances, and since everybody within a generation is identical, this is the same for all. Thus, nominal contracts are optimal, as are many other contracts.

However, when islands differ in size (if $\theta<1$ ), individuals born in different islands have net financial wealth of different size. Nominal IOU contracts, in this case, expose the parties to a risk exactly proportional to their net financial wealth. Whether this form of risk sharing is optimal or not depends on how risk aversion changes with wealth. As shown in the following proposition, if individual preferences exhibit the same degree of constant relative risk aversion, then risk should be borne in proportion to wealth, and nominal contracts are indeed optimal:

Proposition 2. If all households exhibit the same degree of constant relative risk aversion, fixed nominal contracts are optimal even in the presence of shocks to the aggregate rate of population growth.

Proof. As before, an optimal contract maximizes the expected utility of those born on a small island for a given expected utility of those born on a large island. Repeating the procedure outlined in the proof of Proposition 1, we can write the first order condition of this maximum problem as:

$$
\begin{aligned}
& V^{\prime}\left[\frac{F^{S}(\omega, n)}{p^{S}(n)}\right] / p^{S}(n)+V^{\prime}\left[\frac{F^{S}(\omega, n)}{p^{L}(n)}\right] / p^{L}(n) \\
& =\theta \lambda\left\{V^{\prime}\left[\frac{F^{L}(\omega, n)}{p^{S}(n)}\right] / p^{S}(n)+V^{\prime}\left[\frac{F^{L}(\omega, n)}{p^{L}(n)}\right] / p^{L}(n)\right\}
\end{aligned}
$$

where now $F^{k}(\cdot)$ and $p^{k}$ are also contingent on the realization of the population shock, $n$. With a constant relative risk aversion utility function, $V(c)=\frac{c^{1-\alpha}-1}{1-\alpha}, \alpha>0$, the optimality condition (5.2) becomes:

$$
\frac{F^{S}(\omega, n)^{-\alpha}}{p^{S}(n)^{(1-\alpha)}}+\frac{F^{S}(\omega, n)^{-\alpha}}{p^{L}(n)^{(1-\alpha)}}=\theta \lambda\left[\frac{F^{L}(\omega, n)^{-\alpha}}{p^{S}(n)^{(1-\alpha)}}+\frac{F^{L}(\omega, n)^{-\alpha}}{p^{L}(n)^{(1-\alpha)}}\right]
$$

which simplifies to 


$$
\frac{F^{S}(\omega, n)}{F^{L}(\omega, n)}=\theta \lambda^{(-1 / \alpha)}
$$

Condition (5.4) is met for $F^{S}(\omega, n)=F^{S}$ and $F^{L}(\omega, n)=F^{L}$, the case of nominal contracts.

Equation (5.4) reveals that optimal risk sharing under constant relative risk aversion requires that the ratio between the wealth of two members of the same generation born in different types of islands must be the same for all realizations of the aggregate shock. Because some fraction of a household's wealth already lies in its fiat money balances, the simplest way to achieve a proportionate exposure to aggregate risk is to denominate all wealth (net IOUs as well as fiat money) in nominal terms. Hence the optimality of a system of nominal contracts.

Monetary shocks: Suppose now that the rate of growth of fiat money is a serially uncorrelated random variable, that has a time $t$ realization we denote as $z_{t}$. We immediately have:

Proposition 3. If all households exhibit the same degree of constant relative risk aversion, fixed nominal contracts are optimal even in the presence of shocks to the rate of growth of fiat money.

To understand this proposition, it is simply necessary to see from (5.1) that shocks to $z$ have exactly opposite effects on the inflation rate as shocks to $n$. In this way a high realization of $z$ acts exactly like a low realization of $n$ in its effects on a household's wealth. A formal proof of Proposition 3 would therefore follow the steps of Proposition 2.

The possibility of unanticipated inflation puts the real value of a household's nominal wealth at risk. The use of contracts fixed in nominal terms is a simple way to spread this risk evenly across households. ${ }^{10}$

\section{Concluding remarks}

We conclude the paper with a general observation on how the optimality of nominal contracts relates to some fundamental properties of a monetary economy. In the general equilibrium model of the previous pages, fiat money coexists with other assets, it can be dominated in rate of return, and serves as a medium of exchange, as a means of payment and, under general circumstances, as a unit of account. It is a medium of exchange between agents that belong to different generations, who meet only once. It is a means of payment because no centralized market exists in which all contracts can be simultaneously cleared (or, equivalently, the velocity of circulation of con-

\footnotetext{
${ }^{10}$ If instead outside assets are both nominal and real, then risk is (optimally) shared in proportion to net wealth by a combination of nominal contracts and simple equity shares of the real components of wealth. This point is further developed in a previous version of this paper.
} 
tracts is not infinite). Thus, when contracts are settled, the creditor demands to be paid in fiat money knowing that he can exchange only money for commodities later on. Indeed, in this model, without fiat money there can be no credit in equilibrium. Finally, under the conditions discussed in the previous sections, the terms of the contract are expressed in units of fiat money (i.e., they are fixed nominal contracts). Hence money is also a unit of account.

These three roles of money are linked to each other, and are essential to understanding why nominal contracts may be optimal even neglecting computational or information gathering costs. ${ }^{11}$ Money is used as a means of payment precisely because it is also a medium of exchange. And being a means of payment, it is more likely to be used as a unit of account, (i.e., contracts are expressed in fixed nominal terms).

\section{Appendix}

\section{The stationary equilibrium}

Imposing the equilibrium conditions (2.5) and (2.6), equation (4.2a) can be rewritten as:

$$
2 U^{\prime}\left(\theta^{k}\left(1-q^{h}\right)\right)=R^{k} R^{h} \pi\left[V^{\prime}\left(f^{k} \pi\right) q^{k}+V^{\prime}\left(f^{k} \pi q^{k}\right)\right], h, k=S, L \quad h \neq k
$$

where $\theta^{k}=\theta$ if $k=L$ and $\theta^{k}=1 / \theta$ if $k=S, q^{k}$ denotes real money balances in an island of type $k, \pi$ is the inverse of the equilibrium inflation rate, $d^{k}$ is the equilibrium relative price of the good produced in an island of type $k$ in terms of the price of the good produced in $h$, for $h \neq k, R^{k}$ and $R^{h}$ are the nominal interest rates, and $f^{k}$, the net financial wealth of those born in an island of type $k$ expressed in units of commodity $k$, is:

$$
f^{k}=R^{h}\left(1-q^{k}\right)-\theta^{k} d^{h} R^{k}\left(1-q^{h}\right)+q^{k} .
$$

If the cash-in-advance constraint is binding for those born in $k$, then

$$
R^{k}=q^{k} /\left[d^{h} \theta^{k}\left(1-q^{h}\right)\right]
$$

and (A.2) reduces to $f^{k}=R^{h}\left(1-m^{k}\right)$, while the Lagrange multiplier $\mu^{k}$ is obtained from the stationary version of $(4.2 \mathrm{~b})$ :

$$
2 \mu^{k}=\left(R^{h}-1\right) \pi\left[V^{\prime}\left(R^{h}\left(1-q^{k}\right) \pi\right)+V^{\prime}\left(R^{h}\left(1-q^{k}\right) \pi d^{k}\right) d^{k}\right] .
$$

If equations (A.1)-(A.4) have a solution, then a stationary equilibrium exists. For the remainder of this section, we consider the stationary equilibrium in a neighborhood of $\theta=1$. We therefore drop the superscripts $k$ and $h$, since all islands are alike.

\footnotetext{
${ }^{11}$ Niehans (1978), Fama (1983) and White (1984), among others, refer to these computational aspects.
} 


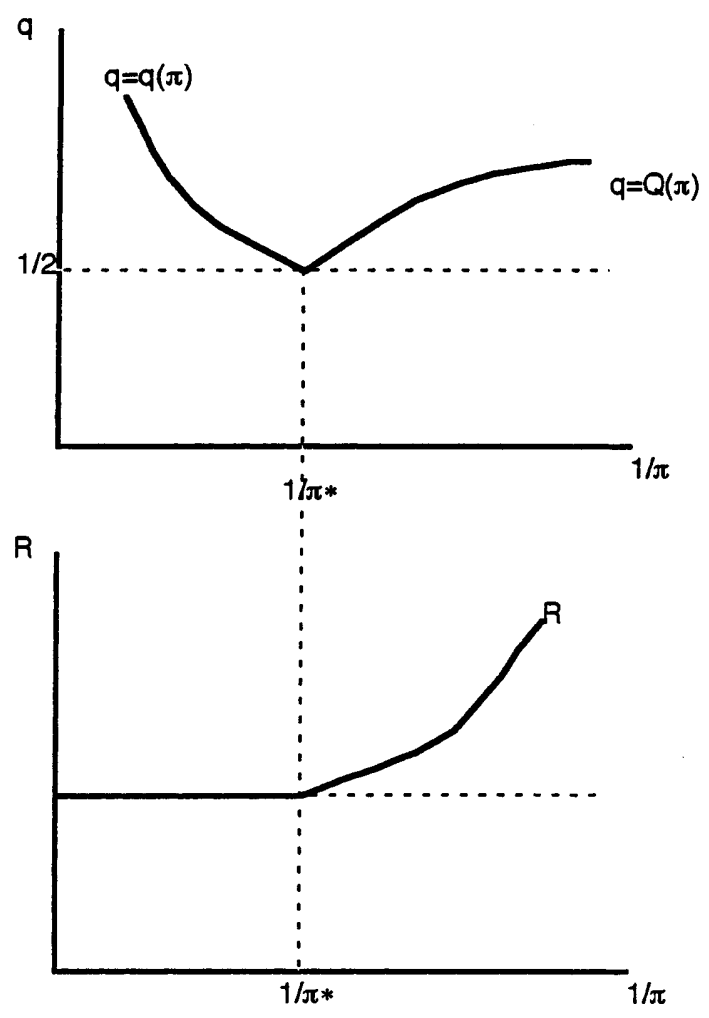

Figure 2

The cash-in-advance constraint (2.4) can be rewritten as:

$$
R \leq q /(1-q) .
$$

When (A.5) is not binding, $R=1$ and real money balances are determined by (A.1), which simplifies to

$$
U^{\prime}(1-q)-\pi V^{\prime}(q \pi)=0 .
$$

Equation (A.6) implicitly defines equilibrium real money balances as a function of $\pi: q=q^{*}(\pi)$. Under the assumption that $V(\cdot)$ has a relative risk aversion coefficient less than $1, q_{\pi}^{*}>0$, that is, real money balances decrease as inflation increases (as $\pi$ drops). This is equivalent to saying that the substitution effect dominates the income effect.

If, on the other hand, (A.5) is binding, then real money balances are determined by

$$
U^{\prime}(1-q)-\pi V^{\prime}(q \pi)\left(\frac{q}{1-q}\right)^{2}=0
$$

which is obtained by combining (A.1) and (A.5). In this equilibrium, real money balances are again a function of $\pi, q=Q^{*}(\pi)$. But here, under the assumption that both $U(\cdot)$ and $V(\cdot)$ have a relative risk aversion coefficient 
smaller than unity, $Q_{\pi}^{*}<0$. That is, higher inflation increases real money balances in equilibrium. The intuition is that when the cash-in-advance constraint binds, higher expected inflation induces households to reduce consumption when young. As everybody does that, sales against IOUs are reduced and sales against cash (and hence real money balances) increase. The key to understanding this result is that the cash-in-advance constraint here binds the repayment of consumption loans, rather than directly the purchase of consumer goods. Finally, note that by (A.5), the interest rate $R$ also rises as $\pi$ drops, since it moves in the same direction as $m$.

Since by (A.5) the cash-in-advance constraint is just binding at $q=1 / 2$, we can summarize the foregoing discussion in the diagrams of Figure 2, where equilibrium real money balances are shown as a non-monotonic function of the inflation rate and the interest rate is first constant and then rising with $1 / \pi$. The threshold inflation rate $1 / \pi^{*}$ such that the cash-inadvance constraint just binds is defined implicitly by the condition obtained from (A.6):

$$
U^{\prime}(1 / 2)-\pi^{*} V^{\prime}\left(\pi^{*} / 2\right)=0 .
$$

Finally, combining (A.1) and (A.4), the Lagrange multiplier $\mu$ on (A.5) can be written as:

$$
\mu=\frac{R-1}{R^{2}} U^{\prime}(1-q) .
$$

Thus, for $R=1, \mu=0$. Whereas for $R>1, \mu$ is a function of $\pi$. Under the same condition mentioned above, that $U(\cdot)$ and $V(\cdot)$ have a relative risk aversion coefficient smaller than unity, and differentiating (A.9) with respect to $\pi$, it is possible to show that $\mu$ is decreasing in $\pi$, and strictly decreasing if $1 / \pi>1 / \pi^{*}$, i.e., the cash-in-advance constraint becomes more binding as inflation increases.

\section{References}

Azariadis, C., Cooper, R.: Predetermined Prices and the Allocation of Social Risks. Quarterly Journal of Economics 100, 495-518 (1985)

Cooper, R.: Labor Contracts and the Role of Monetary Policy in an Overlapping Generations Economy, Journal of Economic Theory 44, 231-250 (1988)

Cooper, R.: Predetermined Wages and Prices and the Impact of Expansionary Government Policy. Review of Economic Studies 57 (2), 205-214 (1990)

Fama, E.: Financial Intermediation and Price Level Control, Journal of Monetary Economics 12, 7-28 (1983)

Gottfries, N.: A Model of Nominal Contracts. Stockholm University Institute for International Economic Studies, Seminar Paper No. 455 (1990)

Haubrich, J., King, R.: Sticky Prices, Money, and Business Fluctuations. Journal of Money, Credit and Banking 23 (2), 243-259 (1991)

Lucas, R.: Equilibrium in a Pure Currency Economy. Economic Inquiry 18, 203-220 (1980)

Mitsui, T., Watanabe, S.: Monetary Growth in a Turnpike Environment. Journal of Monetary Economics 24, 123-137 (1989)

Niehans, J.: The Theory of Money. New York: Johns Hopkins University Press 1978

Smith, B.: A Model of Nominal Contracts. Journal of Labor Economics 7 (4): 392-414 (1989) 
Svensson, L.: Money and Asset Prices in a Cash-in-Advance Economy. Journal of Political Economy 93 (5), 919-944 (1985)

Townsend, R.: Models of Money with Spatially Separated Agents. In: Models of Monetary

Economies, J. H. Kareken, N. Wallace (eds.) Federal Reserve Bank of Minneapolis (1980)

Townsend, R.: Asset-Return Anomalies in a Monetary Economy. Journal of Economic Theory 41, 219-247 (1987)

Townsend, R.: Currency and Credit in a Private Information Economy. Journal of Political Economy, December, 1323-1345 (1989)

White, L.: Competitive Payments Systems and the Unit of Account. American Economic Review 74, 699-712 (1984) 